\title{
Evaluation of $N, N, N$-dimethylbutylammonium methanesulfonate ionic liquid for electrochemical recovery of lead from lead-acid batteries
}

\author{
Sze-yin Tan, ${ }^{\mathrm{a}, *}$ Franky E. Bedoya-Lora, ${ }^{\mathrm{a}, 1}$ Jason P. Hallett, ${ }^{\mathrm{a}}$ Geoffrey H. Kelsall ${ }^{\mathrm{a}}$ \\ ${ }^{a}$ Department of Chemical Engineering, Imperial College London, London SW7 2AZ, UK \\ ${ }^{1}$ Present Address: Centro de Investigación, Innovación y Desarrollo de Materiales - \\ CIDEMAT, Universidad de Antioquia. Cr. 53 No 61 - 30, Torre 2, Lab. 330, Medellín, \\ Colombia
}

\begin{abstract}
Physicochemical and electrochemical properties of $N, N, N$-dimethylbutylammonium methanesulfonate, [DMBA][MS], ionic liquid (IL) have been determined, and the potential application for electrochemical recovery of lead from lead-acid batteries is discussed. To optimise the transport properties of the IL, the dependencies were measured of conductivity, density and viscosity with varying amounts of excess acid with water as a diluent in the electrolyte mixture. The molar conductivity obtained from the molar concentration and ionic conductivity measurements was used to quantify the ionicity of these IL mixtures. The solubility of $\mathrm{Pb}^{\mathrm{II}}$ from $\mathrm{PbCO}_{3}$ was also shown to depend strongly on the IL composition. Preliminary results of the electrochemical kinetics of $\mathrm{Pb}^{\mathrm{II}}$ reduction showed fast $\mathrm{Pb}$ deposition and potential-controlled electrodeposition morphologies of $\mathrm{Pb}$, which may be advantageous for the design of up-scaled lead electrowinning processes.
\end{abstract}

\section{Keywords}

Lead electrodeposition; Electrowinning; Methanesulfonic acid; $N, N, N$ dimethylbutylammonium cations; Transport properties

\section{Highlights}

- $\mathrm{Pb}^{\mathrm{II}}$ solubilities of $0.9 \mathrm{M}$ were measured in [DMBA][MS]

- Molar conductivities exceeded those of a Walden plot's $\mathrm{KCl}$ reference line

- Cyclic voltammograms implied fast $\mathrm{Pb}$ deposition

- Morphologies of $\mathrm{Pb}$ electrodeposits were potential-dependent 


\section{Introduction}

Lead-acid batteries (LABs) are indispensable to the automotive industry due to their mature, robust and well-understood chemistry. Furthermore, they are still present in state-of-the-art hybrid and fully electric vehicles, due to their established market dominance for $12 \mathrm{~V}$ electronics and their ability to deliver high initial bursts of power necessary for the starter ignition of internal combustion engines[1]. Recycling of LABs is an industrial success due to a highly efficient collection supply chain and already accounts for more than $85 \%$ of the total secondary $\mathrm{Pb}$ produced[1,2]. However, conventional $\mathrm{LAB}$ recycling is dominated by pyrometallurgical processes, characterised by high energy consumptions, $\mathrm{CO}_{2}$ production and toxic lead emissions, and reported by Pure Earth in 2016[3] as the most polluting industrial process worldwide.

Despite significant research and development of LAB recycling by ambient temperature hydrometallurgical lead electrowinning and numerous piloted technologies[4-8] developed since the 1980s, electrochemical recycling technologies for LABs have seen less industrial deployment and success than corresponding pyrometallurgical processes. This was due primarily to high capital cost, difficulties in controlling dendritic growth of lead cathodes and anodic side reactions. In recent years, ionic liquids (ILs) have attracted increasing interest as electrolyte media for metal recovery processes[9-12]. Key advantages of IL electrolytes have been reviewed extensively[9-12], but little is understood about the effects of cation/anion compositions on altering electrodeposit morphologies.

Wang et al. investigated the electrodeposition of $\mathrm{Pb}$ on $\mathrm{Au}$ from an 1-methyl-3butylimidazolium chloride- $\mathrm{AlCl}_{3}$ mixture, reporting Moiré-like patterns of $\mathrm{Pb}$ adatoms[13], while Katayama et al. demonstrated the electrochemical separation of $\mathrm{Pb}$ from $\mathrm{Sn}$ in 1-butyl1-methylpyrrolidinium bis(trifluoromethylsulfonyl)imide and the effect of cathode potential on the $\mathrm{Pb}$ deposition morphologies[14]. Simons et al. researched the electrochemistry and deposition of $\mathrm{Pb}$ from 1-ethyl-3-methylimidazolium bis(trifluoromethylsulfonyl)imide, reporting both the electrochemical behaviour and deposition morphologies to be highly dependent on the substrate material[15]. Ru et al used a urea-based deep eutectic solvent (DES) mixture to deposit uniform $\mathrm{Pb}$ wires, reporting the effects of temperature and current density on charge yield, specific electrical energy consumptions and deposit morphologies[16-18]. Liao et al. studied the electrochemical properties of water-insoluble $\mathrm{PbSO}_{4}, \mathrm{PbO}_{2}$ and $\mathrm{PbO}$ phases in urea-choline chloride DES mixtures, reporting similar behaviour for all $\mathrm{Pb}$ compounds studied[19], while Yang et al. reported the potential 
dependence of $\mathrm{Pb}$ deposit morphologies obtained from $\mathrm{PbO}$ dissolved in a urea-choline chloride DES mixtures, from which $\mathrm{Pb}$ deposits exhibited a stretched dendritic morphology with decreasing density with increasing cathodic overpotential[20]. Poll et al. demonstrated $>99.7 \% \mathrm{~Pb}^{\mathrm{II}}$ extraction from lead-based hybrid organic-inorganic perovskite using an ethylene glycol-choline chloride DES mixture via electrowinning[21]. Yeh et al. reported the effect of deposition potential on morphology of $\mathrm{Pb}$ from a Brønsted amide-type ionic liquid, while also demonstrating dissolution of water-insoluble $\mathrm{PbO}$ and $\mathrm{PbO}_{2}$ to form $\mathrm{Pb}^{\mathrm{II}}$ species in the IL[22]. It is important to note that most of these studies focused on the electrochemical behaviour of $\mathrm{Pb}$ in ILs and the deposition morphologies of $\mathrm{Pb}$ films. Studies of $\mathrm{Pb}$ deposition charge yields on long time scales, specific electrical energy consumptions, anodic reaction, $\mathrm{Pb}^{\mathrm{II}}$ solubility and reactor design for $\mathrm{Pb}$ electrowinning have been are less widely reported for IL media compared to aqueous systems[4-8].

Implementation of protic ionic liquids (PILs) in industrial process design has gained popularity due to their low cost[23-25]; PILs are formed by transferring protons from Brønsted acids to Brønsted bases. Depending on the degree of proton transfer during synthesis, PILs can comprise a mixture of the salt, parent acid and parent base. The difference in the aqueous $\mathrm{pK}_{\mathrm{a}}$ values of the parent acid and bases, $\Delta \mathrm{pK}_{\mathrm{a}}$, is generally believed to represent the driving force for the proton transfer in the formation of the PIL[26,27]. For $\Delta \mathrm{pK}_{\mathrm{a}}>3$, it is sufficient for near-complete proton transfer of primary amines, while $\Delta \mathrm{pK}_{\mathrm{a}}>$ 10 is required for complete deprotonation of tertiary amines[26]. This is attributed to differences on hydrogen bonding abilities of the amine species because of steric hindrance of hydrogen bonding to tertiary amines. The PIL $(N, N, N$-dimethylbutylammonium methanesulfonate, [DMBA][MS]) studied herein, gives a $\Delta \mathrm{pK}_{\mathrm{a}}$ value of 8 ; it is assumed that the protonation reaction goes to completion.

To be useful in electrochemical processes, metal ions to be electrodeposited must have high solubilities in chosen ionic liquids, which should have low viscosities to minimise mass transport limitation and to enable high conductivities, to minimise ohmic potential losses across electrolyte solutions. Herein, we report the physical and electrochemical properties of mixtures of [DMBA][MS] with varying amounts of excess acid, with water as a diluent in the electrolyte mixture, as it is ubiquitous and difficult to eliminate from up-scaled processes, but decreases viscosities, so increasing mass transport rates, though possibly increasing hydrogen evolution rates. To our knowledge, results for this solvent system have not been reported previously for a lead electrowinning system and extends our previously reported work, 
comparing the electrochemistry of $\mathrm{Pb}^{\mathrm{II}}$ and electrodeposition morphologies of $\mathrm{Pb}$ in methosulfate-based ILs and aqueous methanesulfonic acid[28].

\section{Experimental}

\subsection{Ionic liquid synthesis and solution preparation}

The $N, N, N$-dimethylbutylammonium methanesulfonate ([DMBA][MS]) ionic liquid was prepared by adding pre-weighed quantities of methanesulfonic acid (MSA) to $N, N, N$ dimethylbutylamine (DMBA) in stoichiometric amounts. This was achieved by dropwise addition of MSA (5.0 M) to DMBA in a round-bottom flask placed in an ice bath. The exothermic reaction (Schematic 1) mixture was stirred for several hours. The formation of the ionic liquid was confirmed by nuclear magnetic resonance (NMR) spectroscopy as previously reported[28]. The base:acid ratios used in this study (1:1.2, 1:1.6 and 1:2) were determined gravimetrically and confirmed by titration with $0.1 \mathrm{M} \mathrm{NaOH}$ using a G20 compact titrator (Mettler Toledo). Water contents were increased systematically (20, 30, 40, 50 and $60 \mathrm{wt} \%$ ), controlled using water addition/evaporation, and confirmed using a volumetric Karl Fischer titrator (Mettler Toledo). The water used in IL synthesis and solution preparation was purified with a Millipore Milli-Q purification system (resistivity $\sim 18.2 \mathrm{M} \Omega \mathrm{cm}$ at $25^{\circ} \mathrm{C}$ ).

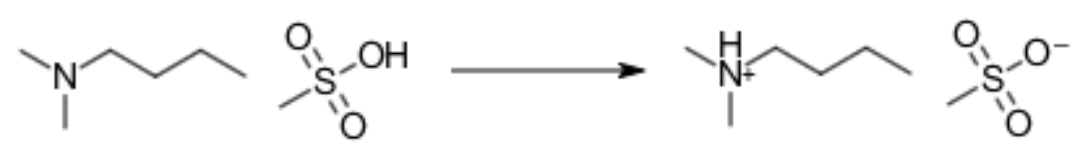

Schematic 1. One-step synthesis of $N, N, N$-dimethylbutylammonium methanesulfonate from $N, N, N$ dimethylbutylamine and methanesulfonic acid.

\subsubsection{Calculations for free acid concentration in [DMBA][MS]}

The excess acid concentration, $c_{\text {excess acid }}$, in the [DMBA][MS]-water mixtures can be estimated from the following:

$$
\begin{gathered}
M_{\text {solution }}=\frac{r_{\mathrm{DMBA}} \cdot M_{w, \mathrm{DMBA}}+r_{\mathrm{MSA}} \cdot M_{w, \mathrm{MSA}}}{\left(1-\frac{w_{\mathrm{H}} \mathrm{O}}{100}\right)} \\
c_{\text {excess acid }}=\frac{r_{\mathrm{MSA}}-r_{\mathrm{DMBA}}}{M_{\text {solution }} / \rho_{\text {solution }}}
\end{gathered}
$$

where $M_{\text {solution }}$ represents the mass of the solution per mole of IL formed, $M_{w, \mathrm{DMBA}}$ and $M_{w, \mathrm{MSA}}$ the molar masses of DMBA and MSA, respectively, $r_{\mathrm{DMBA}}$ the mole ratio of DMBA 
in solution, $r_{\mathrm{MSA}}$ the mole ratio of MSA in solution (1:2, 1:6 or 2), $w_{\mathrm{H}_{2} \mathrm{O}}$ the mass percentage of water in the solution $(20,30,40,50$ or $60 \mathrm{wt} \%)$ and $\rho_{\text {solution }}$ the measured density of the corresponding IL-water solution composition.

\subsubsection{Calculations for molar conductivities}

The molar conductivity, $\Lambda$, of [DMBA][MS]-water mixtures were calculated from the following equations:

$$
\begin{gathered}
\Lambda=K / c_{\text {ions }} \\
c_{\text {ions }}=2 \cdot \frac{\rho_{\text {solution }}\left(1-\frac{w_{\mathrm{H}_{2} \mathrm{O}}}{100}\right)}{r_{\mathrm{DMBA}} \cdot M_{w, \mathrm{DMBA}}+r_{\mathrm{MSA}} \cdot M_{w, \mathrm{MSA}}}
\end{gathered}
$$

where $K$ represents the measured conductivity of the solution and $c_{\text {ions }}$ the total concentration of ions in the solution $\left(\mathrm{DMBA}^{+}, \mathrm{H}^{+}\right.$and $\left.\mathrm{MS}^{-}\right)$.

\subsection{Electrochemistry and electrodeposition experiments}

A glassy carbon disc electrode (1.5 mm radius) served as the working electrode in all cyclic voltammetry, chronoamperometry and chronopotentiometry experiments, using an Autolab PGSTAT302A potentiostat (Metrohm) and NOVA software. Prior to use, the working electrode was polished with a slurry of $0.05 \mu \mathrm{m}$ alumina particles on a soft microfibre polishing pad (MicroCloth, Buehler Ltd.) and then on a clean wet microfibre pad. A platinum gauze acted as the counter electrode and the reference electrode comprised a Ag wire inserted into a glass tube fritted with CoralPor ${ }^{\mathrm{TM}}(7.8 \mathrm{~nm}$ pore size $)$ and filled with 1.0 M MSA solution, producing a stable electrode potential -0.510 vs SHE. This quasi-reference electrode (QRE) was used for all electrochemical experiments regardless of the electrolyte composition.

Electrodeposition experiments used a copper foil (99.9\%, Goodfellow) substrate and a lead wire (Goodfellow, 99.99+\%, As (0.3 ppm), Bi (2.1 ppm), Cu (0.3 ppm) and Ag (0.9 ppm)) as the working electrode and counter electrode, respectively. The choice of copper substrate was to provide an alloy layer to improve the mechanical adhesion of the deposit without catalysing hydrogen evolution. After electrodeposition, the samples were washed with distilled water to remove residual electrolyte from the sample surface and dried in air subsequently. The surface morphologies of the lead deposits on copper foils were imaged with scanning electron microscopy (SEM, JOEL 6010A) coupled with energy dispersive Xray (EDX) to provide element composition identification of the samples. 


\subsubsection{Calculations of diffusion coefficients}

The diffusion coefficients, $D$, of $\mathrm{Pb}^{\mathrm{II}}$ in solution were calculated from $j-t$ curves measured in chronoamperometry experiments by applying the Cottrell equation:

$$
j(t)=n F D^{1 / 2} c \pi^{-1 / 2} t^{-1 / 2}
$$

where $j(t)$ represents the time-dependent current density, $n$ the reaction charge number, $F$ the Faraday constant, $c$ the concentration of electro-active species and $t$ time.

\subsection{Solubility, conductivity, density and viscosity measurements}

\subsubsection{Solubility experiments}

To determine the solubility of $\mathrm{Pb}^{\mathrm{II}}$ species in the IL, $\mathrm{Pb}$-IL solutions were prepared by doping neat IL-water mixtures with excess amounts of $\mathrm{a} \mathrm{Pb}^{\mathrm{II}}$ salt. $\mathrm{PbCO}_{3}$ was used as it is the major component of lead paste from spent $\mathrm{LABs}[1] .6 .4 \mathrm{~g}$ of $\mathrm{PbCO}_{3}\left(1.2 \mathrm{M} \mathrm{Pb}^{\mathrm{II}}\right.$ theoretical maximum) was added to $20 \mathrm{~mL}$ of [DMBA][MS] with varied $r_{\mathrm{DMBA}}: r_{\mathrm{MSA}}$ of 1:1.2, 1:1.6 and $1: 2$ and increasing water content of $w_{\mathrm{H}_{2} \mathrm{O}}=20,3040,50$ and $60 \mathrm{wt} \%$ (15 samples). $\mathrm{PbCO}_{3}$ dissolved into the IL-water mixture by the following reaction:

$$
\mathrm{PbCO}_{3}+2 \mathrm{CH}_{3} \mathrm{SO}_{3} \mathrm{H} \rightarrow \mathrm{Pb}\left(\mathrm{CH}_{3} \mathrm{SO}_{3}\right)_{2}+\mathrm{H}_{2} \mathrm{O}+\mathrm{CO}_{2}
$$

The $\mathrm{Pb}$-IL-water mixtures were stirred for 3 days and the supernatant was filtered through a $45 \mu \mathrm{m}$ Whatman syringe filter. Acid digestion of the $\mathrm{Pb}{ }^{\mathrm{II}}$ saturated IL liquors were carried out with conc. $\mathrm{HNO}_{3}$ in a $1: 10 \mathrm{v} / \mathrm{v}$ ratio ( $1 \mathrm{~mL}$ of IL liquor to $10 \mathrm{~mL} \mathrm{HNO}_{3}$ ). Further dilution was carried out with $2 \% \mathrm{HNO}_{3}$ and the concentration of dissolved $\mathrm{Pb}^{\mathrm{II}}$ was determined using inductively coupled plasma mass spectrometry (ICP-MS, Agilent Technologies) under helium and calibrated against solutions of known $\mathrm{Pb}^{\mathrm{II}}$ concentrations.

\subsubsection{Conductivity, density and viscosity experiments}

The conductivities of the IL-water samples were recorded with a conductivity meter (Jenway, 4330). The densities of the IL-water samples were recorded with a density meter (Mettler Toledo, Easy D30) and their viscosities were determined with a rheometer (Anton Paar, MCR 302). 


\section{Results and Discussion}

\subsection{Solution properties}

\subsubsection{Lead (II) solubility}

Solubilities of $\mathrm{PbCO}_{3}$, expected to depend strongly on the IL composition, are reported in Figure 1 for [DMBA][MS] with $r_{\mathrm{DMBA}}: r_{\mathrm{MSA}}$ of 1:1.2, 1:1.6 and 1:2 and varying water content $\left(w_{\mathrm{H}_{2} \mathrm{O}}=20,30,40,50\right.$ and $\left.60 \mathrm{wt} \%\right)$. A maximum concentration of $\mathrm{Pb}^{\mathrm{II}}$ corresponding to $0.262,0.760$ and $0.912 \mathrm{M}$ was determined in [DMBA][MS] with 1:1.2, 1:1.6 and 1:2, respectively, with $40 \mathrm{wt} \%$ water content.

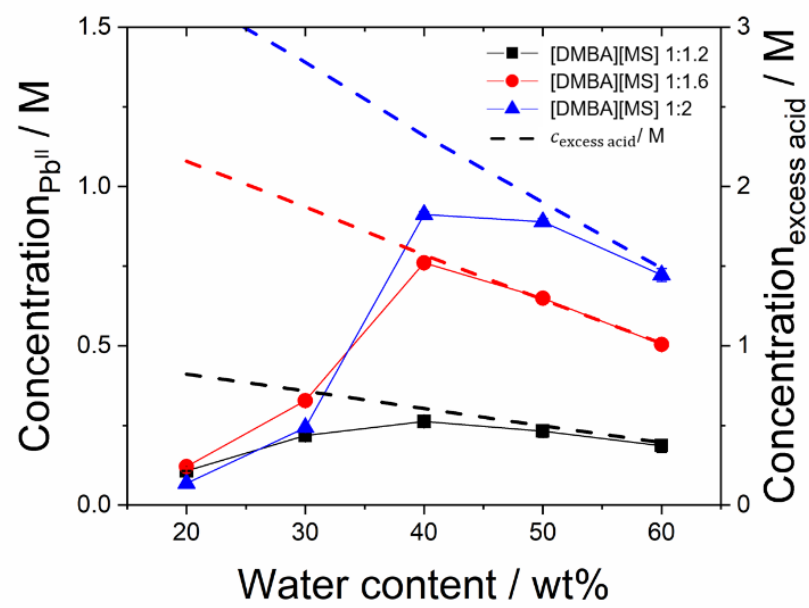

Figure 1. Effect of water content and $r_{\mathrm{DMBA}}: r_{\mathrm{MSA}}$ on solubility of $\mathrm{PbCO}_{3}$ in [DMBA][MS].

To understand the $\mathrm{Pb}^{\mathrm{II}}$ solubility trend in more detail, Figure 1 also shows the concentrations of excess acid in each IL-water composition calculated from Eq. 1 and 2; excess acid concentrations decreased with increasing water content and decreasing $r_{\mathrm{DMBA}}: r_{\mathrm{MSA}}$. From reaction (6), 2 equivalent $\mathrm{H}^{+}$are required to dissolve 1 equivalent of $\mathrm{Pb}^{\mathrm{II}}$ salt. It was observed that the $\mathrm{Pb}^{\mathrm{II}}$ solubility in [DMBA][MS] 1:1.2 and 1:1.6 with $>40 \mathrm{wt} \%$ $\mathrm{H}_{2} \mathrm{O}$ and [DMBA] [MS] 1:2 with $>50 \mathrm{wt} \% \mathrm{H}_{2} \mathrm{O}$ was limited by the concentration of $\mathrm{H}^{+}$ available. At lower $w_{\mathrm{H}_{2} \mathrm{O}}, \mathrm{Pb}^{\mathrm{II}}$ solubilities were lower than expected, and decreased with decreasing wt $\%$ of water, even though high concentrations of $\mathrm{H}^{+}$were present. This has been reported previously for high concentration aqueous MSA solutions[29] and is probably due to incomplete dissociation of the excess MSA in these IL-water compositions which have lower concentrations of water; the IL-water system transitions from aqueous behaviour to IL behaviour as the water content is decreased. 


\subsubsection{Conductivity}

Aqueous electrolytes typically have greater conductivities when compared to organic and IL electrolytes. Hence, understanding the effect of water addition on the conductivity of $[\mathrm{DMBA}][\mathrm{MS}]$ is very important when evaluating the suitability of the IL for a $\mathrm{Pb}$ recovery process design.

Figure 2(a) shows measured conductivities of the [DMBA][MS]-water mixtures at a temperature of $298 \mathrm{~K}$ over a range of water concentrations (20-60 wt \%). The original conductivity data can be found in the Supporting Information, SI. Conductivities of a specific $r_{\mathrm{DMBA}}: r_{\mathrm{MSA}}$ ratio increased with increasing water content. The enhanced conductivities were attributed to increased ion mobility due to the decreasing viscosity with increasing water content. It is also evident that the conductivities of the IL mixtures were dependent on $r_{\mathrm{DMBA}}: r_{\mathrm{MSA}}$ and followed the trend of 1:2>1:1.6>1:1.2, consistent with $\mathrm{H}^{+}$contributing the bulk of the solution conductivity. The relationship between acid concentration, viscosity and conductivity are discussed in more detail in Section 3.1.5.

(a)

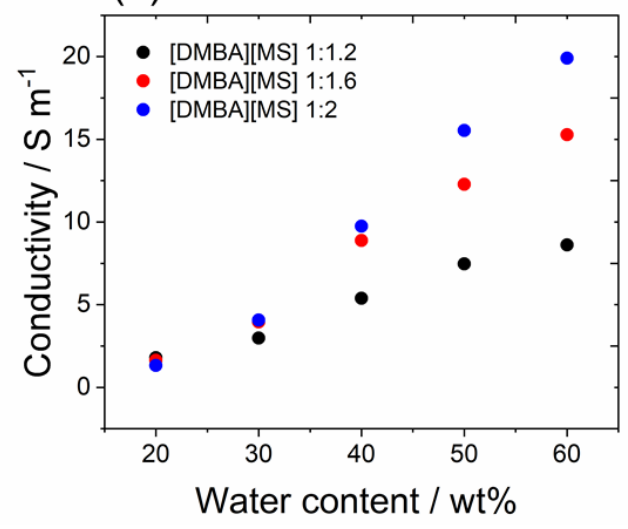

(b)

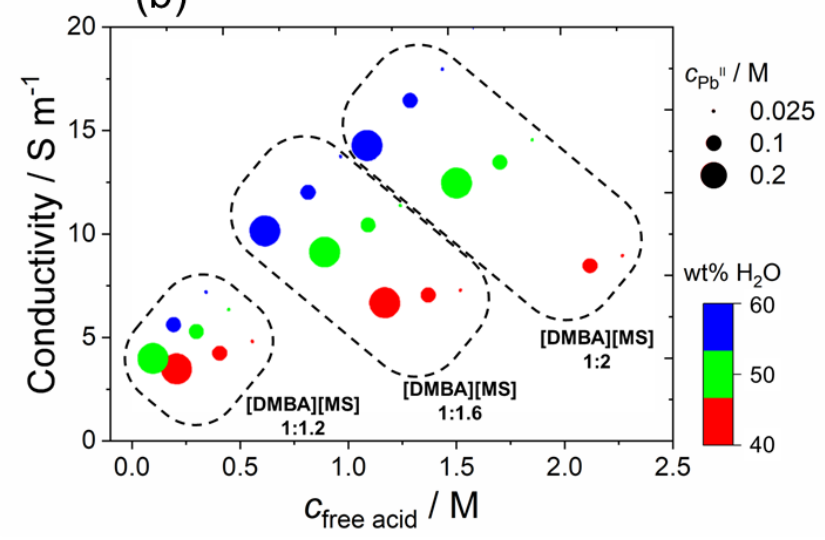

Figure 2. Effects of water content and $r_{\mathrm{DMBA}}: r_{\mathrm{MSA}}$ on conductivities of (a) [DMBA][MS] and (b) $\mathrm{Pb}^{\mathrm{II}}-$ [DMBA][MS] solutions at ambient temperature.

It is also important to note the effect dissolving $\mathrm{Pb}^{\mathrm{II}}$ into the neat IL-water mixtures, as $\mathrm{H}^{+}$is consumed by reaction 6 . Figure 2(b) shows the overall solution conductivities of the ILwater mixtures decreased significantly when increasing amounts of $\mathrm{Pb}^{\mathrm{II}}\left(c_{\mathrm{Pb}^{\mathrm{II}}}=0.025,0.1\right.$ and $0.2 \mathrm{M}$ ) were added; the size of the markers represents the amount of $\mathrm{Pb}^{\mathrm{II}}$ dissolved in the ILwater mixtures and the colours represent the wt $\%$ water in the mixture. Conductivities of the $\mathrm{Pb}^{\mathrm{II}}$-IL-water mixtures are plotted against the concentration of excess acid (calculated from 
Eq. 1 and 2, and accounts for $2 \mathrm{~mol}$ of $\mathrm{H}^{+}$consumed per $1 \mathrm{~mol} \mathrm{~Pb}^{\mathrm{II}}$ dissolved). For each wt\% water content considered, solution conductivities depended approximately linearly on acid concentrations, though the extrapolated lines did not pass through the origin of Figure 2(b).

\subsubsection{Density}

Figure 3(a) shows the effects of water content and $r_{\mathrm{DMBA}}: r_{\mathrm{MSA}}$ on densities of the [DMBA][MS]-water mixtures. For a given $r_{\mathrm{DMBA}}: r_{\mathrm{MSA}}$, densities of the IL-water mixture decreased with increasing water content. Densities of the IL-water mixtures of different $r_{\mathrm{DMBA}}: r_{\mathrm{MSA}}$ increased in the order 1:1.2 $<1: 1.6<1: 2$, as for the conductivity measurements. As shown in Figure 3(b), the density of [DMBA][MS] 1:1.6 with 50 wt $\% \mathrm{H}_{2} \mathrm{O}$ exhibited a small linear decrease over a temperature range of (293-333 K).

(a)

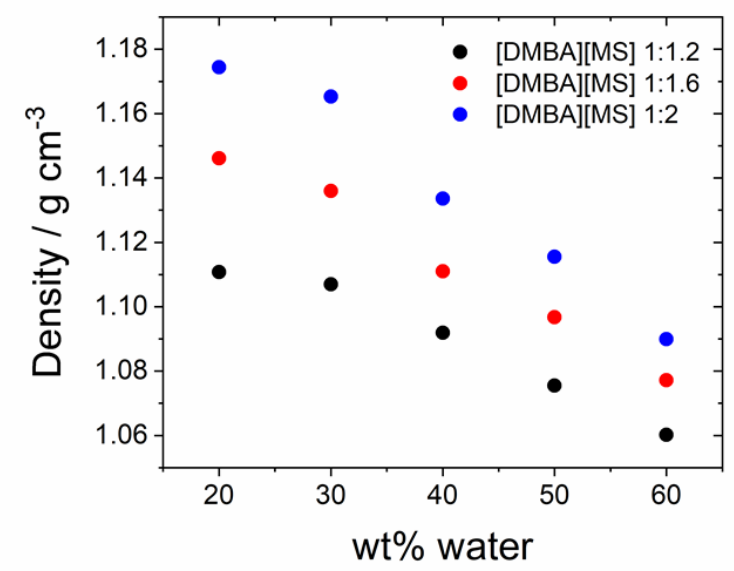

(b)

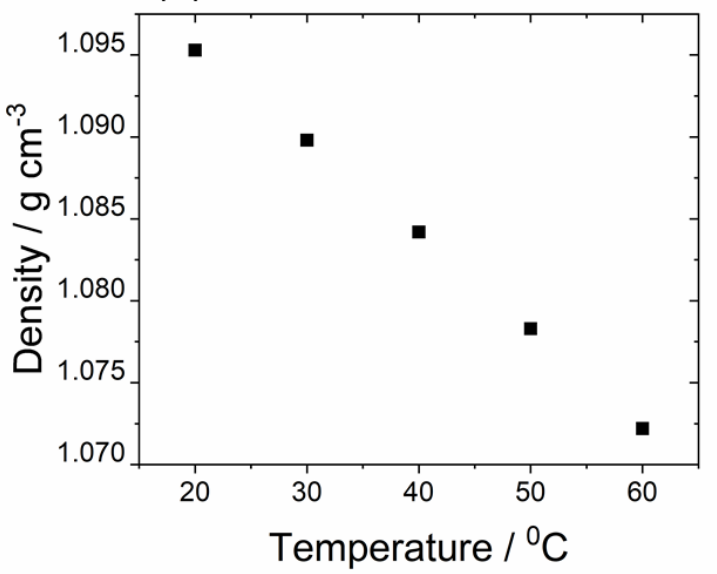

Figure 3. Effects of (a) water content on densities of the IL-water mixture, and (b) solution temperature on the densities of [DMBA][MS] 1:1.6, $50 \mathrm{wt} \% \mathrm{H}_{2} \mathrm{O}$.

\subsubsection{Viscosity}

The viscosity of the IL-water mixtures is another important solution property to be considered in the design of their electrochemical applications, as lower viscosities decrease mass transport limitations. Further, the effect of shear rate on the apparent viscosities of solutions is important when designing flow systems.

Figure 4(a) reports the effect of shear rate on apparent viscosities for [DMBA][MS] 1:1.6 with varying water content $(20,30,40,50$ and $60 \mathrm{wt} \%)$; the effect of increasing the latter parameter was to decrease viscosities very significantly. At shear rates $<10^{2.5} \mathrm{~s}^{-1}$, apparent viscosities were constant and solutions exhibited Newtonian behaviour, whereas at 
shear rates $>10^{2.5} \mathrm{~s}^{-1}$, solution viscosities increased with increasing shear rate, corresponding to shear thickening behaviour, conditions to be avoided when designing an electrochemical system with this IL-water system.

The measured viscosity over the range of low shear rates $<10^{2.5} \mathrm{~s}^{-1}$ was averaged and taken as the absolute viscosity for [DMBA][MS] with $r_{\mathrm{DMBA}}: r_{\mathrm{MSA}}(=1: 1.2,1: 1.6$ and 1:2) and $w_{\mathrm{H}_{2} \mathrm{O}}(=20,3040,50$ and $60 \mathrm{wt} \%)$, as shown in Figure 4(b). The effect of high acid concentration was evident at lower water contents $\leq 30 \mathrm{wt} \%$ with increasing acid content corresponding to increasing viscosity, whereas at high water contents ( $\geq 40 \mathrm{wt} \%)$, the effect of acid concentration on the solution viscosity was negligible.
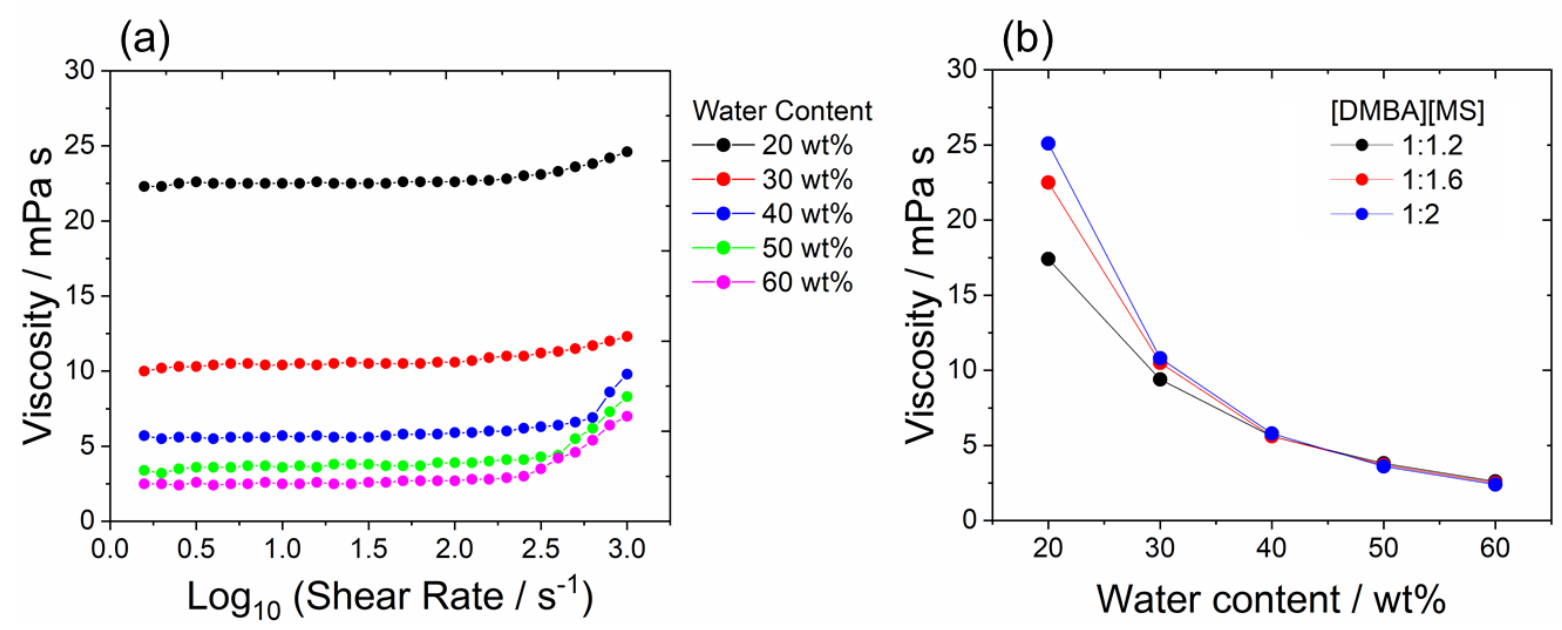

Figure 4. Effects of sheer rate and water content on apparent viscosities (a) for [DMBA][MS] 1:1.6 and (b) for [DMBA][MS] with $r_{\mathrm{DMBA}}: r_{\mathrm{MSA}}(=1: 1.2,1: 1.6$ and $1: 2)$ and $w_{\mathrm{H}_{2} \mathrm{O}}(=20,3040,50$ and $60 \mathrm{wt} \%)$.

\subsubsection{Ionicity}

The Walden plot of $\log \Lambda$ vs. $\log \eta^{-1}$, where $\Lambda$ represents the molar conductivity and $\eta^{-1}$ is the 'fluidity' (inverse viscosity) of the solution, gives a qualitative description of the 'ionicity' of an IL. Data for a (fully ionically dissociated) $0.01 \mathrm{M} \mathrm{KCl}$ solution provides a useful benchmark and reference line, for comparison with data for ILs with known conductivities and viscosities. ILs have been reported to exhibit lower than expected conductivities, even when corrections for viscosity have been considered. This is expected for highly concentrated ionic media in which ion pairs might be sufficiently long-lived and appear neutral under an electric field, strongly influencing solution conductivities[30]. Data that fall below the $0.01 \mathrm{M}$ $\mathrm{KCl}$ reference line imply the presence of neutral ion pairs, neutral ion clusters and nuclear molecules in the IL mixture[31]. Equivalent conductivities that have values above that line 
indicate a decoupling of one of the charge carriers from the structure that determines the viscosity of the IL and is a desirable characteristic for electrochemical processes[32].

Figure 5 shows the Walden plot for [DMBA][MS] with $r_{\mathrm{DMBA}}: r_{\mathrm{MSA}}(=1: 1.2,1: 1.6$ and $1: 2)$, the solution viscosity being varied by changing water content $\left(w_{\mathrm{H}_{2} \mathrm{O}}=20,3040,50\right.$ and $60 \mathrm{wt} \%)$ of the IL-water mixture. The increase in the acid concentration was correlated with increased molar conductance, such that for solutions of the same $w_{\mathrm{H}_{2} \mathrm{O}}$ values, the molar conductivities increased in order of $r_{\mathrm{DMBA}}: r_{\mathrm{MSA}}$ ratios of 1:1.2 $<1: 1.6<1: 2$. The molar conductivity was found to increase with decreasing concentration of [DMBA][MS] and increasing water content. Notably, the molar conductivities of the IL-water mixtures did not follow the same gradient as the reference line for $0.01 \mathrm{M} \mathrm{KCl}$ but exhibited a steeper increase in molar conductivities as increasing amounts of water were added to the IL-water mixtures. In [DMBA][MS] 1:1.6 and 1:2 with > $40 \mathrm{wt} \%$ water, the molar conductivities approached and exceeded the reference line, then showing greater conductivities. Such IL-water compositions would decrease ohmic potential losses in electrolyte solutions of electrochemical reactors[27].

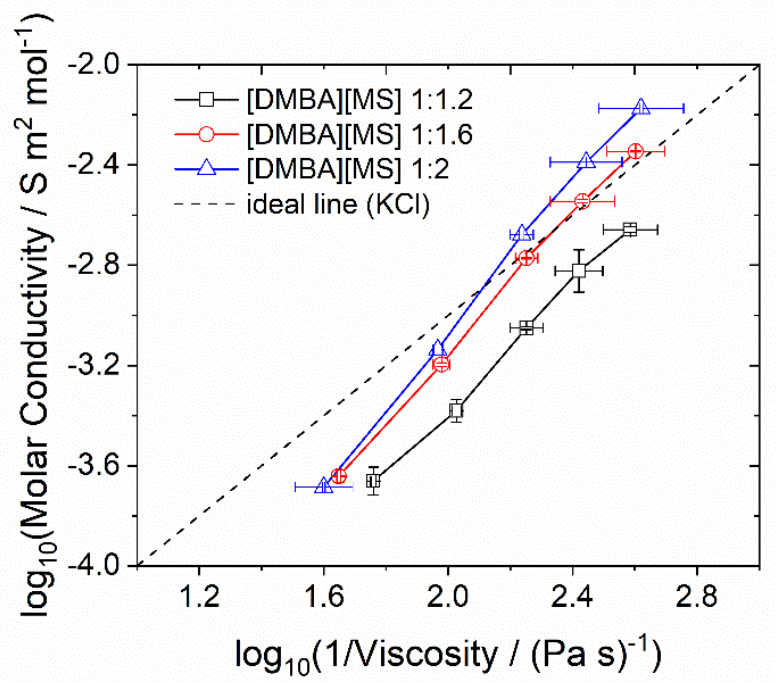

Figure 5. Walden plot for [DMBA][MS] with $r_{\mathrm{DMBA}}: r_{\mathrm{MSA}}\left(=1: 1.2,1: 1.6\right.$ and 1:2) and $w_{\mathrm{H}_{2} \mathrm{O}}(=20,3040,50$ and $60 \mathrm{wt} \%)$. The black dashed line represents the reference line for $0.01 \mathrm{M} \mathrm{KCl}$.

This behaviour is similar to results reported previously by Walsh et al. for PIL, diethylmethylammonium trifluoromethanesulfonate and dimethylbutylammonium trifluoromethanesulfonate[31], for which the addition of water decreased the viscosity, thereby increasing conductivities. However, the trend of increasing conductivities followed the gradient of the reference line and hence the authors concluded that the ion conduction mechanism did not change with the addition of water. However, for the case reported herein, 
a change in the gradient of the reference line with the addition of water, to molar conductivities exceeding those corresponding to the reference line, may imply the occurrence of a Grotthus hopping mechanism[27,31]. Further, Walsh et al. also reported the addition of excess acid to each PIL had negligible effect on the position of the PIL data on the Walden plot, suggesting that the presence of higher concentrations of the parent acid affected neither the conductivity nor the viscosity of the PILs[31]. This behaviour contrasts significantly with results reported here for the [DMBA][MS] system, in which varying amounts of excess acid at higher and lower water contents produced measurable differences in conductivity and viscosity, respectively.

\subsection{Cyclic voltammetry}

Figure 6 shows cyclic voltammograms for the deposition and dissolution of (a) $0.025 \mathrm{M}$ and (b) $0.1 \mathrm{M} \mathrm{Pb}^{\mathrm{II}}$ in [DMBA] [MS] $1: 1.6,50 \mathrm{wt} \% \mathrm{H}_{2} \mathrm{O}$ for 10 repetitive potential cycles. The single cathodic peak produced on the negative-going potential scan is consistent with an overall two-electron reduction of $\mathrm{Pb}^{\mathrm{II}}$ to metallic $\mathrm{Pb}^{0}$ electrodeposits. On the subsequent positive-going potential scan, a single anodic stripping peak occurred, corresponding to the dissolution of metallic $\mathrm{Pb}^{0}$ to $\mathrm{Pb}^{\mathrm{II}}$. The potential $E_{I=0}$, on the positive-going potential scan at which the current, $I=0$, is the estimated formal potential for the $\mathrm{Pb}^{\mathrm{II}} / \mathrm{Pb}^{0}$ couple. $E_{I=0}$ was determined to be $-0.67 \mathrm{~V}$ (vs. Ag QRE) and $-0.65 \mathrm{~V}$ (vs. Ag QRE), respectively, for 0.025 and $0.1 \mathrm{M} \mathrm{Pb}^{\mathrm{II}}$ in [DMBA] [MS] $1: 1.6,50 \mathrm{wt} \% \mathrm{H}_{2} \mathrm{O}$. The measured $E_{I=0}$ value was stable and did not drift over the duration of the repetitive cycling, whereas the cathodic onset potential shifted monotonically towards less negative potentials This is consistent with incomplete stripping of metallic $\mathrm{Pb}^{0}$ nuclei deposited on the previous potential scan and the formation of permanent $\mathrm{Pb}^{0}$ nuclei on the electrode surface which facilitated fast $\mathrm{Pb}$ on $\mathrm{Pb}$ deposition on subsequent cycles.[28] Notably, the peak-to-peak separation, $\Delta E_{p}$, indicated kinetic limitations expected for phase formation processes and were found to be 0.18 and $0.21 \mathrm{~V}$ for 0.025 and $0.1 \mathrm{M} \mathrm{Pb}^{\mathrm{II}}$, respectively, on the first voltammetric scan; these values were far greater than the predicted value of $0.028 \mathrm{~V}$ for a reversible solution phase redox system without the complexities of phase formation. The ratio of charges for dissolution and deposition, $Q_{\mathrm{a}} / Q_{\mathrm{c}}$ was 0.92 on the first voltammetric scan, but increased to ca. 0.96 after 10 scan cycles for the $0.025 \mathrm{M} \mathrm{Pb}^{\mathrm{II}}$ solution, consistent with the formation of permanent $\mathrm{Pb}^{0}$ nuclei on the electrode surface. Conversely, $Q_{\mathrm{a}} / Q_{\mathrm{c}}$ was 0.97 on the first voltammetric scan and decreased to ca. 0.93 after 10 cycles for the $0.1 \mathrm{M} \mathrm{Pb}^{\mathrm{II}}$ solution. This can be explained by the formation of thick deposits of $\mathrm{Pb}$ (possibly dendrites) during the negative-going potential 
scan exemplified by the increased current noise levels measured after 8 potential cycles.

(a) $0.025 \mathrm{M}$

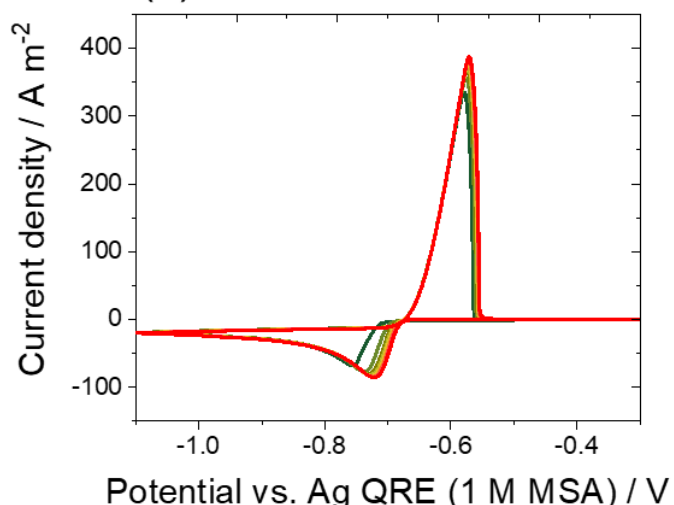

(b) $0.1 \mathrm{M}$

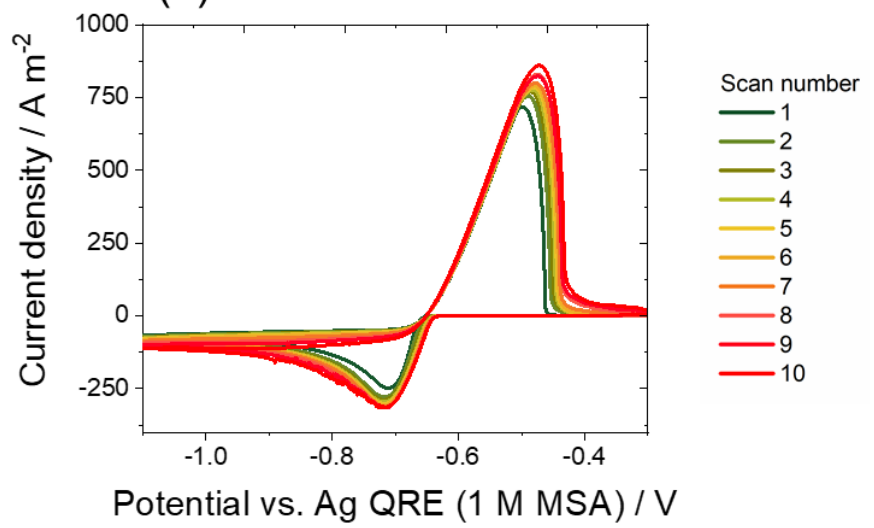

Figure 6. Cyclic voltammograms from repetitive potential cycling of $3 \mathrm{~mm}$ dia. glassy carbon disc electrode in (a) $0.025 \mathrm{M}$ and (b) $0.1 \mathrm{M} \mathrm{Pb}^{\mathrm{II}}$ dissolved in [DMBA][MS] 1:1.6, $50 \mathrm{wt} \% \mathrm{H}_{2} \mathrm{O}$. Initial negative-going potential scan from $-0.3 \mathrm{~V}$ to $-1.1 \mathrm{~V}$ at $0.05 \mathrm{~V} \mathrm{~s}^{-1}$.

Figure 7(i) shows cyclic voltammograms for the deposition/dissolution of 0.025 and 0.1 $\mathrm{M} \mathrm{Pb}^{\mathrm{II}}$ in [DMBA][MS] 1:1.6 with 40, 50 and $60 \mathrm{wt} \%$ water. As the water content of the ILwater mixture was increased, an increase in the deposition peak currents was detected on negative-going potential scans, expectedly as the viscosity of the solution decreased with addition of water, resulting in increased rates of mass transport. Figure 7(ii) shows cyclic voltammograms for the deposition/dissolution of 0.025 and $0.1 \mathrm{M} \mathrm{Pb}^{\mathrm{II}}$ in [DMBA] [MS] 1:1.2, 1:1.6 and 1:2 with $50 \mathrm{wt} \%$ water. Notably, the dissolution peak shifted to more positive potentials with decreasing concentrations of acid, showing increasing limitations of the stripping peak. This was possibly due to insufficient fluxes of methanesulfonate anions to the electrode surface during $\mathrm{Pb}$ stripping, resulting in a positive peak potential shift at lower acid concentrations. It is also important to note that correlations between electron transfer kinetics and viscosity in IL media have also been reported[33] previously and are in agreement with the trend reported herein. Water content and $r_{\mathrm{DMBA}}: r_{\mathrm{MSA}}$ ratios of the IL mixtures did not affect the ratio of charges for dissolution and deposition. 

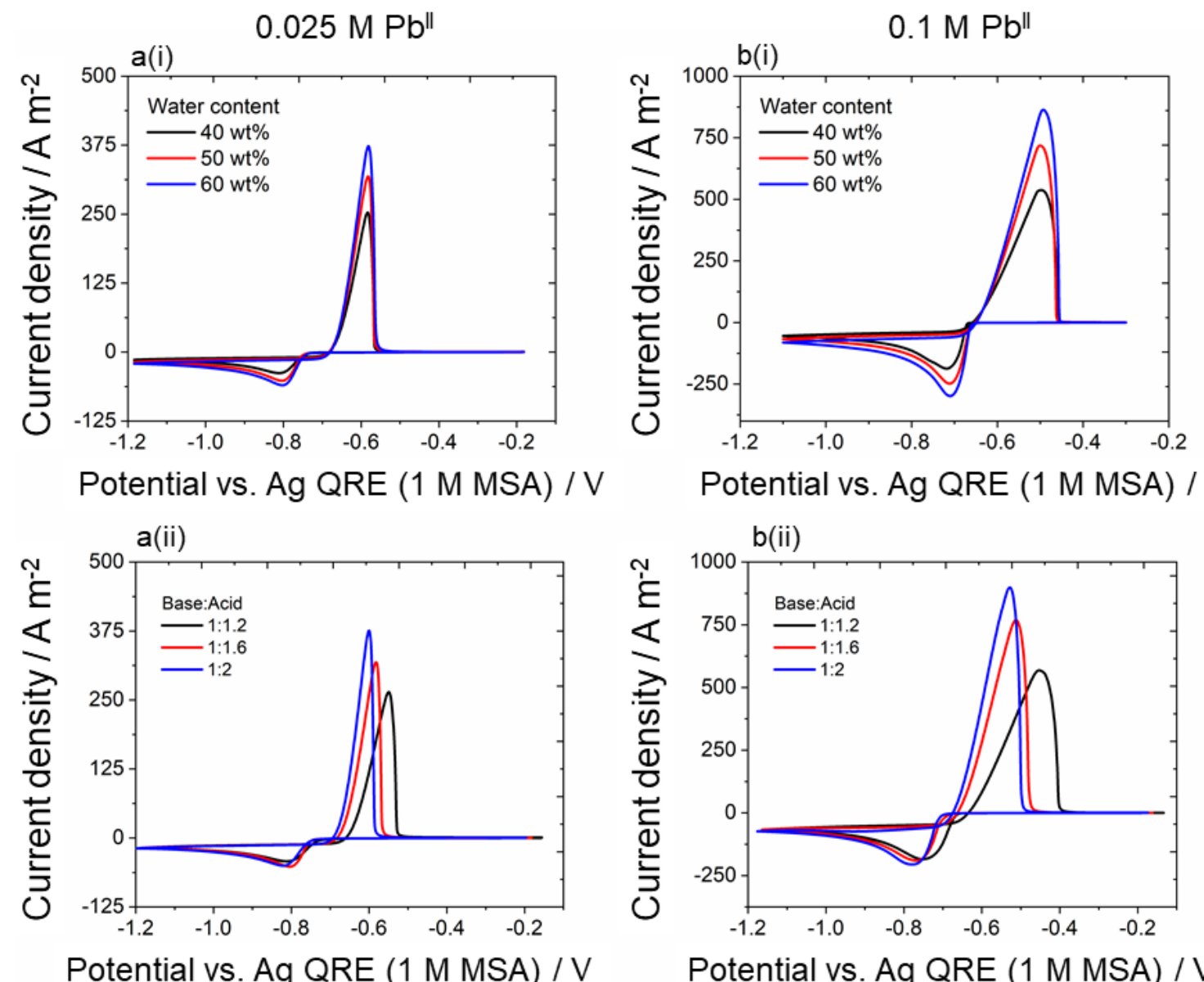

Figure 7. Cyclic voltammograms of $3 \mathrm{~mm}$ dia. glassy carbon disc electrode in (a) $0.025 \mathrm{M}$ and (b) $0.1 \mathrm{M} \mathrm{Pb}^{\mathrm{II}}$ in (i) $[\mathrm{DMBA}][\mathrm{MS}] 1: 1.6$ with varying water content $\left(w_{\mathrm{H}_{2} \mathrm{O}}=40,50\right.$ and $\left.60 \mathrm{wt} \%\right)$ and (ii) [DMBA][MS] with varying base:acid ratios $\left(r_{\mathrm{DMBA}}: r_{\mathrm{MSA}}=1: 1.2,1: 1.6\right.$ and $\left.1: 2\right)$ with $50 \mathrm{wt} \%$ water. Initial negative-going potential scan from $-0.3 \mathrm{~V}$ to $-1.1 \mathrm{~V}$ at $0.05 \mathrm{~V} \mathrm{~s}^{-1}$. Data plotted for first scan on freshly polished electrodes.

\subsection{Chronoamperometry}

The nucleation and growth mechanism of the $\mathrm{Pb}^{0}$ electrodeposits from [DMBA][MS] was investigated by measuring the current transients in response to an applied electrode overpotential step of $-100 \mathrm{mV}$, measured relative to $E_{I=0}$. The dimensionless $I-t$ curves are plotted in Figure 8 for (a) $0.025 \mathrm{M}$ and (b) $0.1 \mathrm{M} \mathrm{Pb}^{\mathrm{II}}$ in [DMBA][MS]-water solution, together with theoretical $I-t$ predictions for two limiting mechanisms of nucleation: instantaneous and progressive. Further description of the nucleation mechanisms can be found in the SI (Section S5), together with relevant equations. From solutions of $0.025 \mathrm{M}$ and $0.1 \mathrm{M}$ $\mathrm{Pb}^{\mathrm{II}}$, clear instantaneous nucleation was operative for all $r_{\mathrm{DMBA}}: r_{\mathrm{MSA}}$ and $w_{\mathrm{H}_{2} \mathrm{O}}$ considered. 
$0.025 \mathrm{M}$
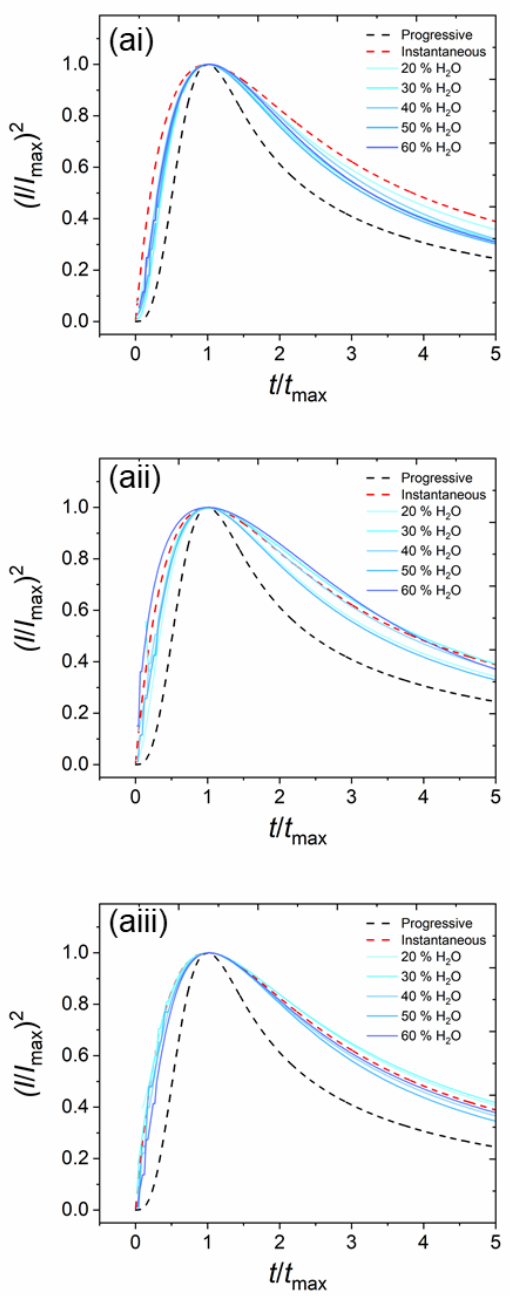

$0.1 \mathrm{M}$
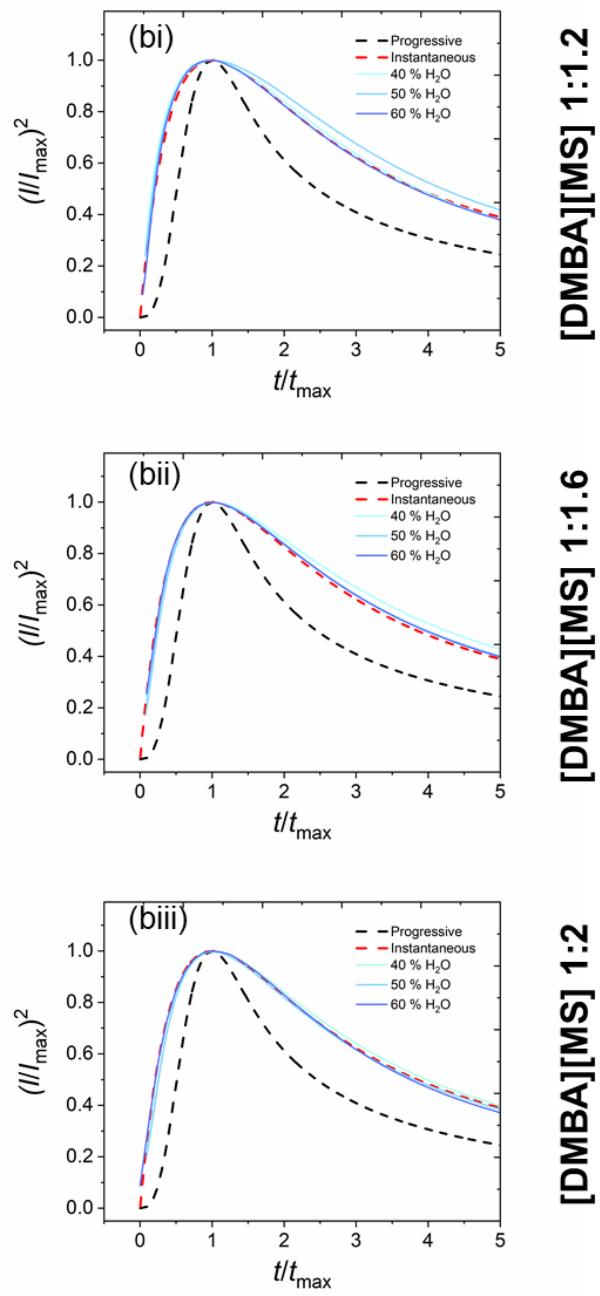

Figure 8. Comparison of the dimensionless theoretical $I$ - $t$ curves for 3-D instantaneous (red) and progressive (black) nucleation under diffusion-controlled growth with experimental curves for (a) $0.025 \mathrm{M}$ and (b) $0.1 \mathrm{M}$ $\mathrm{Pb}^{\mathrm{II}}$ in [DMBA] $[\mathrm{MS}]$ (i) $1: 1.2$, (ii) $1: 1.6$ and (iii) $1: 2$, with 40,50 and $60 \mathrm{wt} \%$ water at a glassy carbon disc electrode at an electrode overpotential of $-100 \mathrm{mV}$.

At longer deposition times, the currents converged and followed diffusion-controlled behaviour predicted by the Cottrell equation (Eq. 5). The calculated diffusion coefficient values from $\mathrm{Pb}^{\mathrm{II}}$ in [DMBA][MS] 1:1.2, 1:1.6 and 1:2 with 20, 30, 40, 50 and $60 \mathrm{wt} \%$ water are summarised in Table S5 and shown in Figure 9. As expected, the diffusion coefficient of $\mathrm{Pb}^{\mathrm{II}}$ in [DMBA][MS] increased with increasing water content, due to a large decrease in solution viscosity, while no distinct trend was evident with the acid content of the IL, expected as [DMBA][MS]-water mixtures with high water content ( $\geq 40 \mathrm{wt} \%$ ) having indistinguishable viscosity regardless of $r_{\mathrm{DMBA}}: r_{\mathrm{MSA}}$ ratio.

As shown in Figure 9(b), the measured diffusion coefficient of $\mathrm{Pb}^{\mathrm{II}}$ was inversely proportional to solution viscosity, as expected from the Stokes-Einstein equation:[33,34] 


$$
D=k_{b} T / c \pi \eta r
$$

where $k_{b}$ represents the Boltzmann constant, $c$ a constant with the values 4 ('perfect slip') or 6 ('perfect stick') and $r$ the Stokes radii for $\mathrm{Pb}^{\mathrm{II}}$.

If the Stokes radius, $r$, is independent of IL composition, it can be calculated by linear regression of the experimental data. The values derived were $2.5 \AA$ and $3.7 \AA$ for perfect 'stick' and 'slip' boundary conditions, respectively. These values are expectedly larger than the ionic radius determined from crystal structures of $\mathrm{Pb}^{\mathrm{II}}$ salts $(1.33 \AA$ ), due to strongly bound solvation of the first coordination shell of the spherical ion in solution. The diffusion behaviour of $\mathrm{Pb}^{\mathrm{II}}$ in [DMBA][MS] is likely to approach 'perfect stick' due to large size differences between $\mathrm{Pb}^{\mathrm{II}}$ ions and the solvent $\left(\mathrm{H}_{2} \mathrm{O}\right)$. Adherence to the Stokes-Einstein relationship for protons,[35] ferrocene,[33,36,37] cobaltocenium,[36,38] and phenylamines [39] in IL media is well reported, but is also contradicted by other reports[4042] of concentration-dependent diffusion coefficient values.
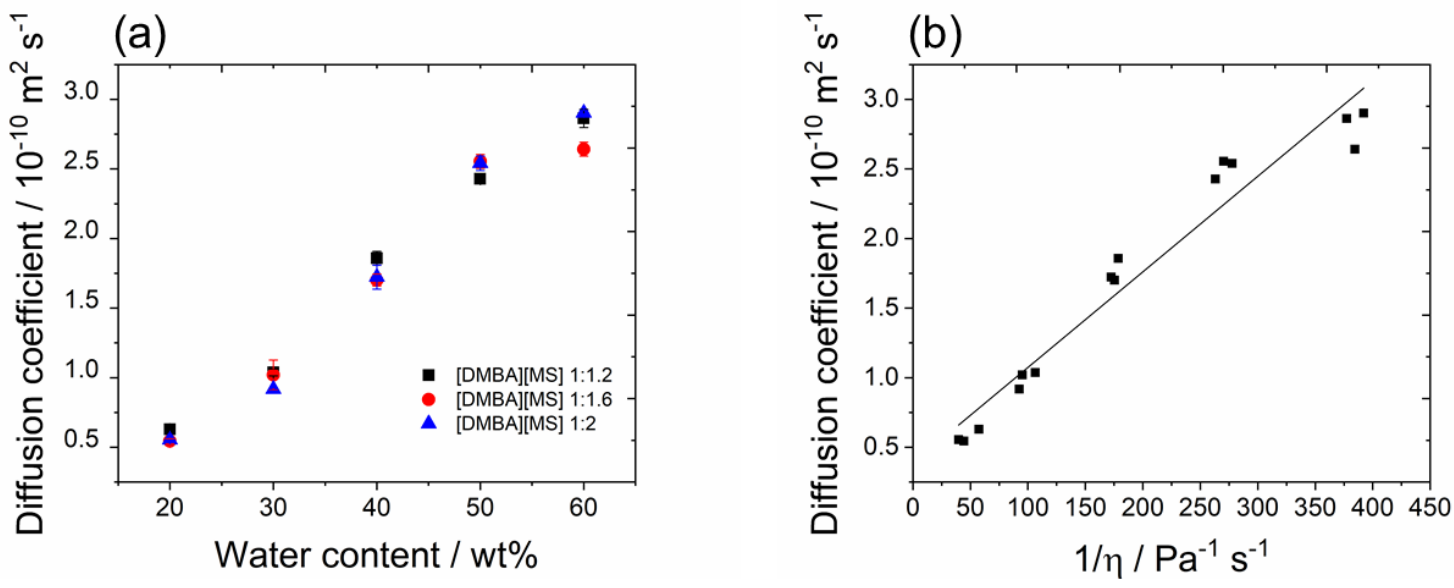

Figure 9. Effects of (a) water content and $r_{\mathrm{DMBA}}: r_{\mathrm{MSA}}$ of $\mathrm{Pb}^{\text {II }}$ in [DMBA][MS] on diffusion coefficients and (b) $1 / \eta$. Diffusion coefficients were calculated using Cottrell equation (5) and chronoamperometric data for 0.025 $\mathrm{M} \mathrm{Pb}^{\mathrm{II}}$ solutions.

\subsection{Pb Deposition morphology}

Dendritic structures are the predominant morphologies obtained from cathodic $\mathrm{Pb}^{0}$ electrodeposition[43-45]. We have reported previously about control of $\mathrm{Pb}^{0}$ electrodeposition morphologies, in the absence of organic additive, by using ILs to obviate dendritic growth of $\mathrm{Pb}^{0}[28]$. Comparing deposits of $\mathrm{Pb}$ on copper foil substrates, a strong influence of electrolyte 
composition was observed with deposit morphologies from 1-butyl-3-methylimidazolium methanesulfonate exhibiting tubular dendritic structures, while deposits from [DMBA][MS] $1: 2,50 \mathrm{wt} \% \mathrm{H}_{2} \mathrm{O}$ resulted in a smooth leaf-like morphology.

Figure 10 shows photomicrographs of $\mathrm{Pb}$ deposits from $0.2 \mathrm{M} \mathrm{PbCO}_{3}$ in [DMBA][MS] 1:1.6, $50 \mathrm{wt} \% \mathrm{H}_{2} \mathrm{O}$ at room temperature, at overpotentials from -100 to $-300 \mathrm{mV}$, measured relative to $E_{I=0}$, and a constant deposition charge density of $2.5 \times 10^{5} \mathrm{C} \mathrm{m}^{-2}$. A significant effect of deposition overpotential was evident. At low overpotentials ( -100 to $-160 \mathrm{mV}), \mathrm{Pb}$ deposition was probably kinetically limited, resulting in a fern-like morphology. At higher overpotentials, (-190 to $-300 \mathrm{mV})$, a spongy network morphology was evident. These deposits were porous and weakly adhering to the copper foil electrode substrates. A similar dependence was observed for $\mathrm{Pb}$ deposits from $0.2 \mathrm{M} \mathrm{PbCO}_{3}$ in [DMBA][MS] 1:1.2, $50 \mathrm{wt} \%$ $\mathrm{H}_{2} \mathrm{O}$ shown in the SI, Figure $\mathrm{S} 1$. Further dependences of $\mathrm{Pb}$ deposition morphologies on electrolyte composition will be reported on in the future.
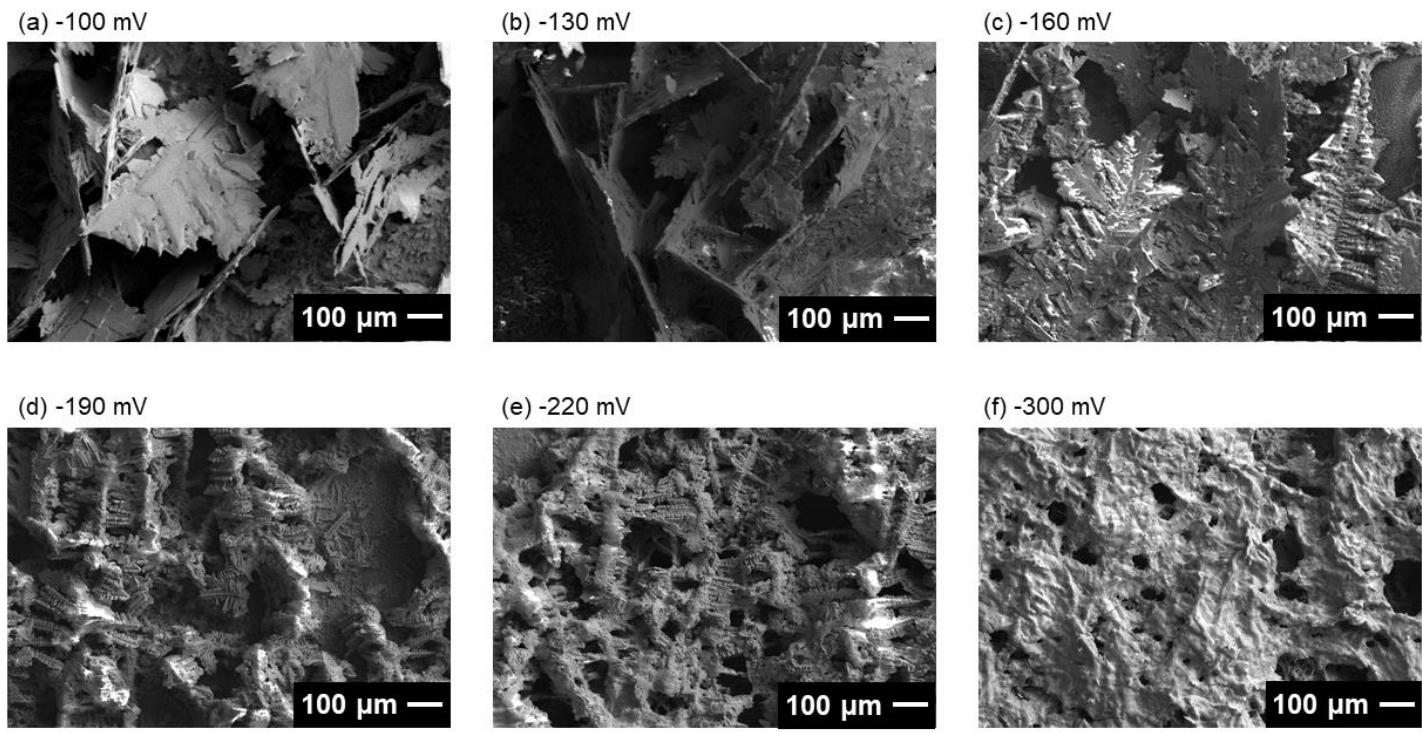

Figure 10. SEM images of $\mathrm{Pb}$ deposits obtained at room temperature on $\mathrm{Cu}$ foil substrates from $0.2 \mathrm{M} \mathrm{PbCO}_{3}$ in [DMBA][MS] 1:1.6, $50 \mathrm{wt} \% \mathrm{H}_{2} \mathrm{O}$ at overpotentials: (a) -100 , (b) -130 , (c) -160 , (d) -190 , (e) -220 and (f) -300 $\mathrm{mV}$. Deposition charge density: $2.5 \times 10^{5} \mathrm{C} \mathrm{m}^{-2}$.

\section{Conclusions}

Methanesulfonate-based ILs offer a promising commercial electrolyte for electrochemical recovery of $\mathrm{Pb}$ from spent lead acid batteries. Transport properties for $N, N, N-$ 
dimethylbutylammonium methanesulfonate ionic liquid, including conductivity, density, viscosity and the ionicity has been studied systematically for a range of excess acid and water content composition. The solubilities of $\mathrm{Pb}^{\mathrm{II}}$ from $\mathrm{PbCO}_{3}$ in the $\mathrm{IL}$, as well as the electrochemical behaviour of such solutions, have also been evaluated. To the best our knowledge, this is the first report of this IL type for the application of Pb electrowinning.

The results demonstrated that physical and electrochemical properties of these IL-water mixtures were highly dependent on the water content and the acid to base ratio of the IL. Solubilities of $\mathrm{Pb}^{\mathrm{II}}$ of $\leq 0.9 \mathrm{M}$ were also determined. As expected, an overall two electron process was operative for $\mathrm{Pb}^{0}$ electrodeposition from $\mathrm{Pb}^{\mathrm{II}}$ containing $N, N, N$ dimethylbutylammonium methanesulfonate. SEM images of $\mathrm{Pb}$ deposits on $\mathrm{Cu}$ foil substrates exhibited potential-dependent deposit morphologies. Further understanding of the role of ILs in the control of mass transport properties, as well as in governing deposition morphologies would facilitate the development of recycling technologies for lead-acid batteries.

\section{Acknowledgements}

The authors thank the UK Engineering and Physical Sciences Research Council for grant EP/P004504/1 providing a research associateship for S.T.

\section{References}

[1] S.-y. Tan, D.J. Payne, J.P. Hallett, G.H. Kelsall, Developments in electrochemical processes for recycling lead-acid batteries, Curr. Opin. Electrochem. 16 (2019) 83-89.

[2] W. Zhang, J. Yang, X. Wu, Y. Hu, W. Yu, J. Wang, J. Dong, M. Li, S. Liang, J. Hu, R.V. Kumar, A critical review on secondary lead recycling technology and its prospect, Renew. Sustain. Energy Rev. 61 (2016) 108-122.

[3] A. Bernhardt, The Toxics Beneath Our Feet, (2016) 1-54.

[4] R. David Prengaman, R.D. Prengaman, Recovering Lead from Batteries, JOM. 47 (1995) $1-2$.

[5] M. Olper, M. Maccagni, C.J.N. Buisman, C.E. Schultz, Electrowinning of Lead Battery Paste with the Production of Lead and Elemental Sulphur Using Bioprocess Technologies, in: Lead-Zinc 2000, John Wiley \& Sons, Inc., Hoboken, NJ, USA, 2013: pp. 803-814.

[6] G. Díaz, D. Martín, C. Frías, F. Sánchez, Emerging applications of ZINCEX and PLACID technologies, JOM. 53 (2001) 30-31.

[7] M. Maccagni, New Approaches on Non Ferrous Metals Electrolysis, Chem. Eng. Trans. 41 (2014) 61-66.

[8] C. Frias, N. Ocaña, G. Diaz, T. Piper, B. Bulkowski, A. Chmielarz, P. Claisse, S. Hemmings, L. Abrantes, H. Jansen, J. Van Erkel, T. Franken, Z. Kunicky, T. Velea, a 
Clean-Lead Factory Is Available for Lead-Acid Batteries Recycling By Means of the " Cleanlead Process ," (2006) 943-951.

[9] A.P. Abbott, G. Frisch, J. Hartley, K.S. Ryder, Processing of metals and metal oxides using ionic liquids, Green Chem. 13 (2011) 471-481.

[10] J. Park, Y. Jung, P. Kusumah, J. Lee, K. Kwon, C. Lee, Application of Ionic Liquids in Hydrometallurgy, Int. J. Mol. Sci. 15 (2014) 15320-15343.

[11] A.P. Abbott, G. Frisch, S.J. Gurman, A.R. Hillman, J. Hartley, F. Holyoak, K.S. Ryder, Ionometallurgy: designer redox properties for metal processing, Chem. Commun. 47 (2011) 10031.

[12] E. Quijada-Maldonado, F. Olea, R. Sepúlveda, J. Castillo, R. Cabezas, G. Merlet, J. Romero, Possibilities and challenges for ionic liquids in hydrometallurgy, Sep. Purif. Technol. 251 (2020) 117289.

[13] F.-X. Wang, G.-B. Pan, Y.-D. Liu, Y. Xiao, Pb deposition onto Au(111) from acidic chloroaluminate ionic liquid, Chem. Phys. Lett. 488 (2010) 112-115.

[14] Y. Katayama, R. Fukui, T. Miura, Electrodeposition of Lead from 1-butyl-1methylpyrrolidinium Bis(trifluoromethylsulfonyl)amide Ionic Liquid, J. Electrochem. Soc. 160 (2013) D251-D255.

[15] T.J. Simons, A.K. Pearson, S.J. Pas, D.R. MacFarlane, The electrochemical cycling and electrodeposition of lead from 1-ethyl-3-methylimidazolium bis(trifluoromethanesulfonyl)imide ionic liquid, Electrochim. Acta. 174 (2015) 712720.

[16] J. Ru, Y. Hua, C. Xu, J. Li, Y. Li, D. Wang, C. Qi, Y. Jie, Morphology-controlled preparation of lead powders by electrodeposition from different $\mathrm{PbO}$-containing choline chloride-urea deep eutectic solvent, Appl. Surf. Sci. 335 (2015) 153-159.

[17] J. Ru, Y. Hua, C. Xu, J. Li, Y. Li, D. Wang, C. Qi, K. Gong, Electrochemistry of $\mathrm{Pb}(\mathrm{II}) / \mathrm{Pb}$ during preparation of lead wires from $\mathrm{PbO}$ in choline chloride - urea deep eutectic solvent, Russ. J. Electrochem. 51 (2015) 773-781.

[18] J. Ru, Y. Hua, C. Xu, J. Li, Y. Li, D. Wang, K. Gong, Z. Zhou, Preparation of submicrometer lead wires from $\mathrm{PbO}$ by electrodeposition in choline chloride-urea deep eutectic solvent, Adv. Powder Technol. 26 (2015) 91-97.

[19] Y. Liao, P. Chen, I. Sun, Electrochemical study and recovery of Pb using 1:2 choline chloride/urea deep eutectic solvent: A variety of $\mathrm{Pb}$ species $\mathrm{PbSO} 4, \mathrm{PbO} 2$, and $\mathrm{PbO}$ exhibits the analogous thermodynamic behavior, Electrochim. Acta. 214 (2016) 265275.

[20] H. Yang, R.G. Reddy, Fundamental Studies on Electrochemical Deposition of Lead from Lead Oxide in 2:1 Urea/Choline Chloride Ionic Liquids, J. Electrochem. Soc. 161 (2014) D586-D592.

[21] C.G. Poll, G.W. Nelson, D.M. Pickup, A. V. Chadwick, D.J. Riley, D.J. Payne, Electrochemical recycling of lead from hybrid organic-inorganic perovskites using deep eutectic solvents, Green Chem. 18 (2016) 2946-2955.

[22] H.W. Yeh, Y.H. Tang, P.Y. Chen, Electrochemical study and extraction of $\mathrm{Pb}$ metal from $\mathrm{Pb}$ oxides and $\mathrm{Pb}$ sulfate using hydrophobic Brønsted acidic amide-type ionic liquid: $\mathrm{A}$ feasibility demonstration, J. Electroanal. Chem. 811 (2018) 68-77.

[23] A. George, A. Brandt, K. Tran, S.M.S.N.S. Zahari, D. Klein-Marcuschamer, N. Sun, N. Sathitsuksanoh, J. Shi, V. Stavila, R. Parthasarathi, S. Singh, B.M. Holmes, T. Welton, B.A. Simmons, J.P. Hallett, Design of low-cost ionic liquids for lignocellulosic biomass pretreatment, Green Chem. 17 (2015) 1728-1734.

[24] F.J.V. Gschwend, A. Brandt, C.L. Chambon, W.-C. Tu, L. Weigand, J.P. Hallett, Pretreatment of Lignocellulosic Biomass with Low-cost Ionic Liquids, J. Vis. Exp. (2016). 
[25] F.J.V. Gschwend, F. Malaret, S. Shinde, A. Brandt-Talbot, J.P. Hallett, Rapid pretreatment of Miscanthus using the low-cost ionic liquid triethylammonium hydrogen sulfate at elevated temperatures, Green Chem. 20 (2018) 3486-3498.

[26] J. Stoimenovski, E.I. Izgorodina, D.R. MacFarlane, Ionicity and proton transfer in protic ionic liquids, Phys. Chem. Chem. Phys. 12 (2010) 10341-10347.

[27] M. Yoshizawa, W. Xu, C.A. Angell, Ionic Liquids by Proton Transfer: Vapor Pressure, Conductivity, and the Relevance of $\Delta \mathrm{p} \mathrm{K}$ a from Aqueous Solutions, J. Am. Chem. Soc. 125 (2003) 15411-15419.

[28] S.-y. Tan, J.P. Hallett, G.H. Kelsall, Electrodeposition of lead from methanesulfonic acid and methanesulfonate ionic liquid derivatives, Electrochim. Acta. 353 (2020) 136460.

[29] A. Hazza, D. Pletcher, R.G.A. Wills, A novel flow battery: A lead acid battery based on an electrolyte with soluble lead(ii), Phys. Chem. Chem. Phys. 6 (2004) 1773.

[30] D.R. MacFarlane, M. Forsyth, E.I. Izgorodina, A.P. Abbott, G. Annat, K. Fraser, On the concept of ionicity in ionic liquids, Phys. Chem. Chem. Phys. 11 (2009) 4962-4967.

[31] S.E. Goodwin, D.E. Smith, J.S. Gibson, R.G. Jones, D.A. Walsh, Electroanalysis of Neutral Precursors in Protic Ionic Liquids and Synthesis of High-Ionicity Ionic Liquids, Langmuir. 33 (2017) 8436-8446.

[32] C. Austen Angell, Y. Ansari, Z. Zhao, Ionic Liquids: Past, present and future, Faraday Discuss. 154 (2012) 9-27.

[33] C.L. Bentley, J. Li, A.M. Bond, J. Zhang, Mass-Transport and Heterogeneous ElectronTransfer Kinetics Associated with the Ferrocene/Ferrocenium Process in Ionic Liquids, J. Phys. Chem. C. 120 (2016) 16516-16525.

[34] P.C.F. Pau, J.O. Berg, W.G. McMillan, Application of Stokes' law to ions in aqueous solution, J. Phys. Chem. 94 (1990) 2671-2679.

[35] C.L. Bentley, A.M. Bond, A.F. Hollenkamp, P.J. Mahon, J. Zhang, Mass transport studies and hydrogen evolution at a platinum electrode using bis(trifluoromethanesulfonyl)imide as the proton source in ionic liquids and conventional solvents, J. Phys. Chem. C. 118 (2014) 29663-29673.

[36] E.I. Rogers, D.S. Silvester, D.L. Poole, L. Aldous, C. Hardacre, R.G. Compton, Voltammetric Characterization of the Ferrocene | Ferrocenium and Cobaltocenium | Cobaltocene Redox Couples in RTILs, J. Phys. Chem. C. 112 (2008) 2729-2735.

[37] A. Lewandowski, L. Waligora, M. Galinski, Ferrocene as a reference redox couple for aprotic ionic liquids, Electroanalysis. 21 (2009) 2221-2227.

[38] A. Lewandowski, L. Waligora, M. Galinski, Electrochemical behavior of cobaltocene in ionic liquids, J. Solution Chem. 42 (2013) 251-262.

[39] R.G. Evans, O. V. Klymenko, C. Hardacre, K.R. Seddon, R.G. Compton, Oxidation of $N, N, N^{\prime}, N^{\prime}$-tetraalkyl-para-phenylenediamines in a series of room temperature ionic liquids incorporating the bis(trifluoromethylsulfonyl)imide anion, J. Electroanal. Chem. 556 (2003) 179-188.

[40] S. Eisele, M. Schwarz, B. Speiser, C. Tittel, Diffusion coefficient of ferrocene in 1-butyl3-methylimidazolium tetrafluoroborate - concentration dependence and solvent purity, Electrochim. Acta. 51 (2006) 5304-5306.

[41] L. Nagy, G. Gyetvai, L. Kollár, G. Nagy, Electrochemical behavior of ferrocene in ionic liquid media, J. Biochem. Biophys. Methods. 69 (2006) 121-132.

[42] C.A. Brooks, A.P. Doherty, Concentration-dependent diffusion in room temperature ionic liquids: a microelectrode study, Electrochem. Commun. 6 (2004) 867-871.

[43] E.R. White, S.B. Singer, V. Augustyn, W.A. Hubbard, M. Mecklenburg, B. Dunn, B.C. Regan, In situ transmission electron microscopy of lead dendrites and lead ions in aqueous solution, ACS Nano. 6 (2012) 6308-6317.

[44] H.M. Liaw, J.W. Faust, Effect of growth parameters on habit and morphology of 
electrodeposited lead dendrites, J. Cryst. Growth. 18 (1973) 250-256.

[45] M. Sun, H.G. Liao, K. Niu, H. Zheng, Structural and morphological evolution of lead dendrites during electrochemical migration, Sci. Rep. 3 (2013) 1-6. 